\title{
1 Mechanisms of $\beta$-lactam resistance of Streptococcus uberis isolated from 2 bovine mastitis cases
}

\author{
3 Scott McDougall ${ }^{a}$, Laura Clausen ${ }^{a}$, Hye-Jeong Ha ${ }^{\text {b }}$, Isobel Gibsonc, Mark Bryand, Nazreen \\ $4 \quad$ Hadjirine, Elizabeth Laye, Claire Raisene, Xiaoliang Ba ${ }^{e}$, Olivier Restife, Julian Parkhill ${ }^{\mathrm{e}}$ and \\ $5 \quad$ Mark A. Holmese \\ 6 a Cognosco, Anexa FVC, Morrinsville, New Zealand \\ $7 \quad{ }^{b}$ Animal Health laboratory, Ministry for Primary Industry, Upper Hutt, New Zealand \\ 8 'New Zealand Veterinary Pathology, Hamilton, New Zealand \\ 9 'VetSouth, Winton, New Zealand \\ 10 eDepartment of Veterinary Medicine, University of Cambridge, Madingley Road, Cambridge, UK \\ 11 Wellcome Sanger Institute, Hinxton, UK \\ 12 "Corresponding author at: PO Box 21, Morrinsville, New Zealand, 3300: Tel: +64 7889 5159, Fax: \\ 13 +64 7889 3681, Email address: smcdougall@anexafvc.co.nzPage Break
}

\begin{abstract}
14 Abstract
15 A number of veterinary clinical pathology laboratories in New Zealand have been reporting 16 emergence of increased minimum in inhibitory concentrations for $\beta$-lactams in the common 17 clinical bovine mastitis pathogen Streptococcus uberis. The objective of this study was to 18 determine the genetic basis of this increase in MIC for $\beta$-lactam amongst $S$. uberis. Illumina 19 sequencing and determination of oxacillin MIC was performed on 265 clinical isolates.

20 Published sequences of the five penicillin binding proteins $p b p 1 a, p b p 1 b, p b p 2 a, p b p 2 b$, and $21 \quad \operatorname{pbp} 2 x$ were used to identify, extract and align these sequences from the study isolates.
\end{abstract}


Amino acid substitutions resulting from single nucleotide polymorphisms (SNP) within these

23 genes were analysed for associations with elevated $(\geq 0.5 \mathrm{mg} / \mathrm{L})$ oxacillin MIC together with a genome wide association study. The population structure of the study isolates was approximated using a phylogenetic tree generated from an alignment of the core genome. A total of $53 \%$ of isolates had MIC $\geq 0.5 \mathrm{mg} / \mathrm{L}$ for oxacillin. A total of 101 substitutions within the five $p b p$ were identified, of which 11 were statistically associated with an MIC $\geq 0.5$ mg/L. All 140 isolates which exhibited an increased $\beta$-lactam MIC had SNPs leading to $p b p 2 x \mathrm{E}_{381} \mathrm{~K}$ and $\mathrm{Q}_{554} \mathrm{E}$ substitutions. The phylogenetic tree indicated that the genotype and phenotype associated with the increased MIC for oxacillin were present in several different lineages suggesting that acquisition of this increased $\beta$-lactam MIC had occurred in multiple geographically distinct regions. Reanalysis of the data from the intervention studies from which the isolates were originally drawn found a tendency for the $p b p 2 x \mathrm{E}_{381} \mathrm{~K}$ substitution to be associated with lower cure rates. It is concluded that there is geographically and genetically widespread presence of $p b p$ substitutions associated with reduced susceptibility to $\beta$-lactam antimicrobials. Additionally, presence of $p b p$ substitutions tended to be associated with poorer cure rate outcomes following antimicrobial therapy for clinical mastitis.

Key words: Streptococcus uberis; $\beta$-lactam resistance; penicillin binding proteins

\section{Introduction}

Streptococcus uberis is a common bovine mastitis pathogen (Bradley et al., 2007; McDougall et al., 2007b). Its core genome consists of 1,530 genes and it is a highly recombinant species (Lang et al., 2009). Streptococcus uberis is highly heterogeneous as indicated by strain typing including random amplified polymorphic DNA (RAPD) fingerprinting, multilocus sequencing typing (MLST), and pulsed field gel electrophoresis 
(PFGE) (Zadoks et al., 2011). Isolates from the UK and New Zealand have been shown to have distinct MLST patterns, with a preponderance of ST-143 in New Zealand isolates, while ST-5 was predominant among the UK isolates (Pullinger et al., 2006). S. uberis may behave either as an environmental or contagious pathogen. Contagious transmission has been demonstrated through longitudinal studies and inferred from cross sectional studies in which al., 2003).

Bacteriological cure rates following therapy of clinical $S$. uberis are reported to range between 64 and 91\% (McDougall, 1998; McDougall et al., 2007a; Owens et al., 1997). Many factors influence the cure rate following mastitis therapy, including antimicrobial resistance (Sandholm et al., 1990). Because they do not produce $\beta$-lactamase (Zapun et al., 2008), Streptococci have historically been regarded as highly susceptible to $\beta$-lactams which are still the therapy of choice for infections with these bacteria. However, phenotypically $\beta$-lactam resistant bovine $S$. uberis isolates have been reported with bimodal distributions of minimum inhibitory concentrations (MIC) for cloxacillin in French, German and New Zealand studies

60 (Guérin-Faublée et al., 2003; McDougall et al., 2014; Tenhagen et al., 2006). of cell wall peptidoglycan. Six $p b p$ are found in S. pneumoniae: five high-molecular-mass pbp (pbpla, pbp1b, pbp2x, pbp2a, and pbp2b) and one low-molecular-mass PBP (pbp3). pbp $2 a$ and $2 b$ are essential, at least in $S$. pneumoniae, as double deletion results in nonviability (Peters et al., 2016). The active site of transpeptidase activity is formed by three conserved amino acid motifs, SXXK, SXN, and $\mathrm{KT}(\mathrm{S}) \mathrm{G}$. $\beta$-lactam resistance is generally associated with changes within, or flanking, these motifs. Mutations that confer resistance have only been described in the penicillin binding domains, that is, the transpeptidase 
69 domains (Hakenbeck et al., 2012a). Low affinity variants of all the $p b p$ have been described

70 (Hakenbeck et al., 1999), but only mutations of pbpla, $-2 x$, and $-2 b$ appear to be associated

with clinical $\beta$-lactam resistance (Grebe and Hakenbeck, 1996; Nagai et al., 2002). Low level resistance occurs with amino acid substitutions in $p b p 2 b$ or $2 x$, while high level resistance requires additional amino acid substitutions in $p b p 1 b$ or $p b p 3$ (Du Plessis et al., 2002; Smith and Klugman, 1998). Alterations in the conserved motifs in $p b p 2 b$ tend to be associated with resistance to penicillin, and alterations in $p b p 2 x$ appear to contribute to low-level resistance to cephalosporins (Nagai et al., 2002). There is evidence of horizontal gene transfer amongst the streptococci, with a common resistance gene pool for S. pneumoniae, S. oralis and S. mitis (Dowson et al., 1994; Hakenbeck et al., 2012a). There is variation in the affinity of different $\beta$-lactams to $p b p$ variants, which may reduce the clinical efficacy of different $\beta$-lactams in the face of emerging resistance (Garau, 2002; Grebe and Hakenbeck, 1996) in streptococci. It has been shown that resistant $S$. uberis isolates generated in the laboratory arise from alterations in $p b p 1 a, p b p 2 b$ and/or $p b p 2 x$ (Haenni et al., 2010b). $\beta$-lactam resistance mechanisms independent of substitutions amongst the $p b p$ have been reported including the presence of a murMN/fibAB operon, a mutation in the gene coding for GlcNAc deacetylase, and mutations in the gene $\operatorname{mraY}$ (Chewapreecha et al., 2014; Hakenbeck et al., 2012b).

This study was undertaken to test the hypothesis that increases in MIC in clinical $S$. uberis isolates are associated with amino acid substitutions in one or more of the $p b p$.

\section{Materials and Methods}

Streptococcus uberis isolates collected during the conduct of two clinical mastitis antimicrobial therapy intervention studies were used for this study (Bryan et al., 2016; McDougall et al., 2019). The isolates were obtained from mastitic milk of cows prior to 
treatment from a total of 35 dairy farms in New Zealand (North Island and South Island) and were collected with permission of Animal Ethics Committees.

Isolates that were Gram positive cocci, catalase negative, cleaved esculin, sorbitol and inulin and which did not grow in SF broth were initially defined as S. uberis. All isolates were subcultured onto an entire 5\% blood agar plate containing 1\% aesculin (Fort Richard, Auckland, New Zealand). From a pure culture, a single colony was picked and inoculated onto a Dorset egg slope (Fort Richard, Auckland, New Zealand), incubated overnight at $37^{\circ} \mathrm{C}$ and checked for growth before storage at $4{ }^{\circ} \mathrm{C}$ for further testing. The species of isolates was confirmed by MALDI-TOF (Pathology Associates LTD, Pathlab Bay of Plenty Division, Tauranga, New Zealand).

\subsection{Susceptibility testing}

The MIC of oxacillin was determined using a broth microdilution method according to CLSI standards (CLSI, 2013) using cation-adjusted Mueller-Hinton broth supplemented with 2.5\% lysed horse blood (CAMHB-LHB). Oxacillin solutions were prepared in CAMHB-LHB to a concentration range double of that the desired final concentrations of 0.0325 to $16 \mathrm{mg} / \mathrm{L}$ and dispensed into 96-well plates at $50 \mu \mathrm{l}$ per well. Inoculum was prepared using colony suspension method to a turbidity equivalent to that of a $0.5 \mathrm{McF}$ arland standard and was diluted 1:100 in CAMHB-LHB. For each test isolate, $50 \mu 1$ of diluted isolate inoculum was added to the wells. Each isolate was tested in triplicate. The 96-well plates were then placed in a plastic bag to minimize evaporation and incubated at $35^{\circ} \mathrm{C}$ for $20 \mathrm{~h}$. Oxacillin was selected as we wished to determine the MIC for the penicillinase-stable penicillins including cloxacillin, which is commonly used for treatment of both clinical (Bryan et al., 2016, and subclinical mastitis at the end of lactation. The oxacillin MIC for the 265 isolates were used 
to determine the epidemiological cut off (ECOFF) values by fitting a series of mixture models (Everitt, 1996) to the log-transformed MIC by maximum likelihood.

Additional antibiotic susceptibility data was generated during the original clinical studies using either eTest (Biomerieux, France) or a custom-designed broth microdilution (Sensititre, Trek Diagnostics, Thermo Fisher, OH, USA) for penicillin, cefalexin, cefuroxime, ceftiofur, and cefquinome for subsets of the isolates. Streptococcus pneumoniae (ATCC 49619) was run as a quality-control organism in parallel with the unknown isolates and the results were within the CLSI defined quality assurance standards.

\subsection{Molecular biology}

Genomic DNA was extracted from overnight cultures using the MasterPure Gram Positive DNA Purification Kit (Cambio, UK). Illumina library preparation was carried out as previously described (Quail et al., 2008), and sequencing performed on an Illumina HiSeq 2000 following the manufacturer's standard protocols (Illumina, Inc, USA) at the Welcome Sanger Institute, Hinxton, UK (WSI).

\subsection{Bioinformatics}

Assemblies and annotations were generated using pipelines at the WSI (Page et al., 2016). Assemblies were imported into Geneious (version 10.2.2, Geneious Inc, NZ) for analysis. The sequences for $p b p 1 a, 1 b, 2 a, 2 b$ and $2 x$ were obtained from O140J S. uberis genome (NCBI accession number AM946015) and used to identify these genes in the study isolates. The $p b p$ genes were extracted, aligned and single nucleotide polymorphisms (SNP) associated with amino acid substitution were identified. Amino acid sequences were aligned (and numbered) with those previously reported (Haenni et al., 2010b) for $p b p 1 a, 2 b$ and $2 x$, while amino acid numbering relative to the start of the open reading frame were used for $p b p 1 b$ and $2 a$. 
For comparison with the sequence data from the study isolates, the sequences of $13 \mathrm{UK}$

S. uberis (Hossain et al., 2015) were downloaded from European nucleotide archive

(http://www.ebi.ac.uk/ena) and 63 Canadian S. uberis sequences were downloaded from

PATRIC (www.patricbrc.org) (Vélez et al., 2017).

Multilocus sequence types were determined from the genome sequenced data (Coffey et al., 2006) (http://pubmlst.org/suberis).

A core genome alignment was obtained using Roary (Page et al., 2015) and a maximum likelihood phylogenetic tree was constructed using Randomized Accelerated Maximum Likelihood (RAxML)(Stamatakis, 2014). This tree was annotated using iTOL (Letunic and Bork, 2016).

Initial associations between non-synonymous SNPs and the presence of an MIC above the ECOFF were examined using bivariate $\left(\chi^{2}\right)$ statistics and binary logistic regression analyses. Subsequently forward and reverse multivariate logistic regression models were constructed to which all SNPS that were significant $(\mathrm{P}<0.05)$ at the bivariate level were offered. This analysis was undertaken in STATA v10.2 (Stata Corp., College Station, TX, USA). Comparisons of MIC amongst other $\beta$-lactams for the specific SNPs were undertaken using Kruskal-Wallis non-parametric analyses, and regression analyses were used to compare the MIC of oxacillin with the MICs for other $\beta$-lactams.

Subsequently a genome wide association study (GWAS) was undertaken using the oxacillin resistance MIC as the outcome using sequence element enrichment analysis (SEER; https://github.com/johnlees/seer) (Lees et al., 2016) and visualised using Phandango (Hadfield et al., 2017). K-mers (10-593bp) were generated from the isolate assemblies using FSM-lite. For the population structure an initial distance matrix was prepared using Mash 
(Ondov et al., 2016), which was projected onto a final distance matrix into 6 dimensions (selected on the basis of a Scree plot, data not shown) using R (script available at MRC Climb; climb.ac.uk) (Connor et al., 2016). SEER was then used to determine if any k-mers were associated with the cloxacillin resistance phenotype using a threshold adjusted for multiple testing of $\mathrm{P}<5 \times 10^{-8}$ (Barsh et al., 2012).

Frequency of recombination events within the $S$. uberis genomes was estimated by performing a Genealogies Unbiased By recombinations In Nucleotide Sequences (Gubbins) analysis, (https://github.com/sanger-pathogens/Gubbins; Croucher et al 2015). A Roary alignment tree was used as the starting tree, the alignment was undertaken using SMALT, with O140J as the reference, and visualised using Phandango (Hadfield et al., 2017).

\subsection{Cure following intramammary therapy}

The association between the presence of the $\mathrm{E}_{381} \mathrm{~K}$ substitution in $p b p 2 x$ and cure rate (defined as absence of signs of clinical mastitis and/or non-isolation of the bacteria associated with clinical mastitis pre-treatment at 2 or 3 time points post treatment) following intramammary therapy was examined independently for the isolates from the two intervention studies. In the first study quarters with clinical mastitis were infused on three occasions at 24 hour intervals with either $1 \mathrm{~g}$ penicillin and $200 \mathrm{mg}$ cloxacillin (PenClox 1200 High Potency Milking Cow, Virbac, (NZ) Ltd, Hamilton, NZ), or with a combination of $200 \mathrm{mg}$ oxytetracycline, $100 \mathrm{mg}$ oleandomycin, $100 \mathrm{mg}$ neomycin and $5 \mathrm{mg}$ prednisolone (Mastalone, Pfizer NZ Ltd., Auckland, NZ) (Bryan et al., 2016). In the second intervention study affected quarters were treated by intramammary infusion at 12 hourly intervals with $200 \mathrm{mg}$ amoxycillin (as amoxycillin trihydrate), $50 \mathrm{mg}$ clavulanic acid (as potassium clavulanate), and $10 \mathrm{mg}$ prednisolone (Clavulox LC, Zoetis New Zealand Limited, Auckland, New Zealand) on three or five occasions (McDougall et al., 2019). 
Generalised linear mixed models were used to assess the effect of treatment, $\mathrm{E}_{381} \mathrm{~K}$

$187 \quad \operatorname{pbp} 2 x$ genotype, and the treatment by genotype interaction on cure. For the first intervention 


\subsection{Associations between SNPs and oxacillin resistance}

At a bivariate level, the 11 most common SNPs (i.e. present in $\geq 26(10 \%)$ of the isolates) were associated with an oxacillin MIC greater or equal to the ECOFF within the transpeptidase domains of pbpla, $2 b$ and $2 x$, and pbplb and $2 a$ (Table 1).

Of the 141 isolates having an oxacillin MIC greater or equal to the ECOFF, 140 of

these had the $p b p 2 x \mathrm{E}_{381} \mathrm{~K}, \mathrm{Q}_{554} \mathrm{E}$, and $\mathrm{G}_{600} \mathrm{E}$ substitutions. There was only one isolate without the $\mathrm{E}_{381} \mathrm{~K}$ substitution that had an oxacillin MIC greater or equal to the ECOFF as it had an oxacillin MIC of $1 \mathrm{mg} / \mathrm{L}$. A total of 133 of the isolates with an oxacillin MIC greater or equal to the ECOFF also had a $p b p 2 x \mathrm{~V}_{590} \mathrm{~A}$ substitution, and all of the $\mathrm{V}_{590} \mathrm{~A}$ also had the $\mathrm{E}_{381} \mathrm{~K}$, $\mathrm{Q}_{554} \mathrm{E}$, and $\mathrm{G}_{600} \mathrm{E}$ substitutions. There was no difference in the oxacillin MIC for isolates that did or did not have the $\mathrm{V}_{590} \mathrm{~A}$ substitution within isolates with the $\mathrm{E}_{381} \mathrm{~K}$ substitution $(1.79 \pm$ $0.57 \mathrm{mg} / \mathrm{L}$ vs $1.66 \pm 0.48 \mathrm{mg} / \mathrm{L}$ for isolates with and without the $\mathrm{V}_{590} \mathrm{~A}$ substitution within the $\mathrm{E}_{381} \mathrm{~K}$ substitution; $\left.\mathrm{P}=0.05\right)$.

The $\mathrm{E}_{381} \mathrm{~K}$ substitution was also associated with increases in $\mathrm{MIC}$, relative to isolates without the substitution, for penicillin, cefuroxime, ceftiofur, and cefquinome, but with a decrease in MIC for cefalexin (Table 2; Fig. 3). There was a positive association between oxacillin MIC and the MICs for penicillin $\left(\mathrm{R}^{2}=0.58 ; \mathrm{P}<0.001\right)$, cefuroxime $\left(\mathrm{R}^{2}=0.60 ; \mathrm{P}<\right.$ $0.001)$, ceftiofur $\left(\mathrm{R}^{2}=0.29 ; \mathrm{P}<0.001\right)$, ampicillin $\left(\mathrm{R}^{2}=0.63 ; \mathrm{P}<0.001\right)$, cefquinome $\left(\mathrm{R}^{2}=\right.$ $0.43 ; \mathrm{P}<0.001)$ and ampicillin/clavulanic acid $\left(\mathrm{R}^{2}=0.19 ; \mathrm{P}<0.001\right)$, but a negative association between oxacillin and cefalexin $\left(\mathrm{R}^{2}=0.07 ; \mathrm{P}<0.001\right)$.

There were 5 non-synonymous SNPs in the transpeptidase domain of $p b p 2 x$ gene of the 13 UK and 63 Canadian isolates (Table 1). All these variants, except the $\mathrm{A}_{492} \mathrm{E}$ substitution, were also found in the New Zealand isolates. 
Multivariable models for oxacillin resistance did not converge if any one of the $\mathrm{E}_{381} \mathrm{~K}$,

$\mathrm{Q}_{554} \mathrm{E}$, and $\mathrm{G}_{600} \mathrm{E}$ substitutions and any other SNPs were included.

232

233

234

235

\subsection{Multilocus sequence typing and Phylogenetic analysis}

A total of 146 sequence type were identified by MLST in the New Zealand isolates, a proportion of which had not previously been described (listed in Supplementary Table 1).

While there was an association between MLST type and presence of the $p b p 2 x \mathrm{E}_{381} \mathrm{~K}$ substitution $(\mathrm{P}<0.001)$, the $\mathrm{E}_{381} \mathrm{~K}$ substitution was widely distributed throughout the phylogenetic tree and not found exclusively within one lineage (Supplementary Fig. 1).

\subsection{GWAS}

In the genome wide association study, the Manhattan plot (Supplementary Fig. 2) reveals a high level of association (peaking at $\mathrm{P}<10^{-12}$ ) of k-mers within $p b p 2 x$ and three other genes positioned next to this gene. Statistically significant candidate loci were detected in the $\operatorname{pbp} 2 x$ and mraY peptidoglycan biosynthesis pathway, and in two other genes yxeM and $y x e N$. There were a total of 27, 42 and 11 SNPs in the mraY, yxeM, and yxeN genes, respectively of which 10, 18 and 4 were non-synonymous. There were 3, 2, and 1 nonsynonymous SNPs with a prevalence of $>20 \%$ on $\operatorname{mraY}$, yxeM, and yxeN genes, respectively, all of which were associated $(\mathrm{P}<0.001)$ with the $b p b 2 x \mathrm{E}_{381} \mathrm{~K}, \mathrm{Q}_{554} \mathrm{E}$, and $\mathrm{G}_{600} \mathrm{E}$ substitutions. No statistically significant SNPs were found in the $\operatorname{csh} B$ gene located between $m r a Y$ and yxeM.

\subsection{Gubbins analysis}

A high level of genomic recombination was observed amongst the $S$. uberis genomes 


\section{7 Cure rate}

253

In the first intervention study (Bryan et al., 2016), there was no significant effect of

254 Treatment $(\mathrm{P}=0.99), p b p 2 x \mathrm{E}_{381} \mathrm{~K}$ substitution $(\mathrm{P}=0.13)$, or the treatment $x p b p 2 x \mathrm{E}_{381} \mathrm{~K}$

255 substitution interaction $(\mathrm{P}=0.41)$ on cure rate. However, the cure rate was numerically lower

256 in quarters affected with $S$. uberis with the $\mathrm{E}_{381} \mathrm{~K}$ substitution where treatment occurred with

257 the $\beta$-lactam treatment (approximately $15 \%$ lower cure rate), while the cure rate of the $\mathrm{E}_{381} \mathrm{~K}$

258 substitution was 4\% lower following treatment with the non- $\beta$-lactam (Fig. 4a).

259

260

261

In the second study (McDougall et al., 2019), presence of the $\mathrm{E}_{381} \mathrm{~K}$ substitution tended $(\mathrm{P}=0.07)$ to reduce bacteriological cure rate (Fig. $4 b)$. While not significant $(\mathrm{P}=0.11)$, numerically there appeared to be an interaction with the duration of treatment, whereby isolates with the $\mathrm{E}_{381} \mathrm{~K}$ substitution treated for a longer duration ( $5 \mathrm{x} 12$ hourly) had higher bacteriological cure rates than isolates treated for a shorter period ( $3 \times 12$ hourly), whereas duration of treatment did not affect cure rate amongst the isolates without the substitution.

\section{Discussion}

A bimodal distribution of MICs for oxacillin was observed for S. uberis isolated from cases of bovine mastitis. A total of $53 \%$ of isolates had an MIC greater than the ECOFF of $\geq$ $0.5 \mathrm{mg} / \mathrm{L}$. isolates with MICs greater than the ECOFF were present on 28 of 30 farms located both in the North and South islands of New Zealand, indicating wide geographic distribution and a low probability of direct cow to cow transmission of isolates with an MIC greater than the ECOFF.

SNPs with possible association with the oxacillin MICs greater than the ECOFF were found on all $5 p b p$ (pbpla, $1 b, 2 a, 2 b$ and $2 x$ ). Following multivariable modelling, those on pbp $2 x$ resulting in a $\mathrm{E}_{381} \mathrm{~K}$ substitution were found to account for the observed increased MIC 
for oxacillin. This finding was confirmed by the results from a GWAS, which identified only pbp $2 x$ and 3 genes flanking this region.

Substitutions in $p b p 1 b$ and $p b p 2 a$ have not been previously reported in S. uberis.

However, substitutions in all $p b p$ associated with phenotypic resistance have been reported to occur in $S$. pneumoniae (Hakenbeck et al., 2012a). The $p b p 1 b \mathrm{G}_{768} \mathrm{~S}$ and the $p b p 2 a \mathrm{~T}_{397} \mathrm{~A}$ substitutions were also found in the Canadian and UK isolates, demonstrating wide geographic distribution of these substitutions.

On $p b p 2 b, 4$ of the substitutions previously induced (Haenni et al., 2010b) were also observed in the current study in New Zealand, Canada and the UK; $\mathrm{N}_{366} \mathrm{I}, \mathrm{T}_{402} \mathrm{I}, \mathrm{V}_{570} \mathrm{~A}$ and $\mathrm{P}_{575} \mathrm{~S}$. Three other substitutions were located in $p b p 2 b$ in the New Zealand isolates, but none of these were associated with an increased MIC for oxacillin. As previously reported (Haenni et al., 2010b), the $\mathrm{N}_{366}$ I substitution was located 13 residues downstream of the SVVK motif, the $\mathrm{T}_{402} \mathrm{I}$ SNP was located six residues before the SSN motif, and the $\mathrm{V}_{570} \mathrm{~A}$ and $\mathrm{P}_{575} \mathrm{~S}$ SNPs were located nine and four residues upstream of the KTG motif, respectively.

For $p b p 2 x$, five substitutions associated with an increased MIC for oxacillin were located in the present study. All 5 were also located in the Canadian and UK isolates. The $\mathrm{E}_{381} \mathrm{~K}$ and $\mathrm{Q}_{554} \mathrm{E}$ substitutions were previously reported as occurring in naturally occurring and induced resistant $S$. uberis (Haenni et al., 2010b), being 42 amino acids downstream of the STMK motif and five amino acids downstream of the KTG motif, respectively. All isolates with the $p b p 2 x \mathrm{E}_{381} \mathrm{~K}, \mathrm{Q}_{554} \mathrm{E}$, and $\mathrm{G}_{600} \mathrm{E}$ substitutions had oxacillin $\mathrm{MIC} \geq 0.5 \mathrm{mg} / \mathrm{L}$. Of the eight isolates with the $p b p 2 x \mathrm{~A}_{590} \mathrm{~V}$ substitution, seven of these also had the $p b p 2 x \mathrm{E}_{381} \mathrm{~K}$, $\mathrm{Q}_{554} \mathrm{E}$, and $\mathrm{G}_{600} \mathrm{E}$ substitutions. This suggests that $p b p 2 x \mathrm{E}_{381} \mathrm{~K}, \mathrm{Q}_{554} \mathrm{E}$, and $\mathrm{G}_{600} \mathrm{E}$ substitutions are the functionally important ones, rather than the $\mathrm{A}_{590} \mathrm{~V}$ substitution. The mechanism of 
resistance for the one isolate without the $\mathrm{E}_{381} \mathrm{~K}, \mathrm{Q}_{554} \mathrm{E}$, and $\mathrm{G}_{600} \mathrm{E}$ substitutions that had an elevated oxacillin MIC remains to be determined.

The $p b p 2 x \mathrm{Q}_{554} \mathrm{E}$ substitution has been described in other penicillin resistant

301

302

303

304

305

306

307

308

309

310

311

312

streptococci (Haenni et al., 2018). Restoring the wild type genotype at this position results in 8 to 16 fold reduction in MIC (Dahesh et al., 2008), demonstrating the importance of this substitution. The $p b p 2 x \mathrm{E}_{381} \mathrm{~K}$ substitution has not been described in Streptococci other than $S$. uberis (Haenni et al., 2010b; Hakenbeck et al., 2012a). The biological effect of the newly identified substitutions $\left(\mathrm{I}_{295} \mathrm{~V}, \mathrm{~V}_{590} \mathrm{~A}, \mathrm{G}_{600} \mathrm{E}, \mathrm{G}_{600} \mathrm{D}\right)$ are unclear. These substitutions were identified in all 3 populations of isolates examined. These substitutions were highly correlated with the $\mathrm{E}_{381} \mathrm{~K}, \mathrm{Q}_{554} \mathrm{E}$, and $\mathrm{G}_{600} \mathrm{E}$ substitutions, hence in the current population the increased MIC for oxacillin could be entirely explained by the presence of the $\mathrm{E}_{381} \mathrm{~K}$ and $\mathrm{Q}_{554} \mathrm{E}$ substitutions. The $\mathrm{V}_{590} \mathrm{~A}, \mathrm{G}_{600} \mathrm{E}, \mathrm{G}_{600} \mathrm{D}$ substitutions are located in the $\alpha$-helix of the transpeptidase domain. In $S$. pneumoniae, a $\mathrm{N}_{605} \mathrm{~T}$ substitution is associated with decreased acetylation and reduced sensitivity to $\beta$-lactam antimicrobials (Carapito et al., 2006) and sitedirected mutagenesis has demonstrated that the reversion of the resistant $\mathrm{Y}_{595} \mathrm{~F}$ substitution reduces the MIC (Smith and Klugman, 2005). Both of these substitutions are also within the $\alpha$-helix of the transpeptidase domain (Hakenbeck et al., 2012a). Taken together these data suggest that the newly identified substitutions could contribute to reduced susceptibility of $S$. uberis to $\beta$-lactam antimicrobials.

The $\mathrm{E}_{381} \mathrm{~K}, \mathrm{Q}_{554} \mathrm{E}$, and $\mathrm{G}_{600} \mathrm{E}$ substitutions were also associated with increased MIC for other $\beta$-lactams including penicillin, ceftiofur, cefquinome, amoxicillin/clavulanic acid and cefuroxime. Only ceftiofur has a validated bovine mastitis clinical breakpoint ( $2 \mathrm{mg} / \mathrm{L})$ and only 2 of 265 isolates in the current study had an MIC $>2 \mathrm{mg} / \mathrm{L}$. For the other $\beta$-lactams, the maximum MIC were $0.5 \mathrm{mg} / \mathrm{L}$ for penicillin, $1 \mathrm{mg} / \mathrm{L}$ for cefquinome, and $2 \mathrm{mg} / \mathrm{L}$ for 
cefuroxime, cephalexin and 2/1 mg/L for amoxicillin/clavulanic acid. In the absence of

clinical breakpoints, while bimodal distributions for many of these antimicrobials were

present, the clinical significance of this remains unclear. However, following intramammary infusion of $1 \mathrm{~g}$ of penicillin, which is a commonly used therapy in New Zealand, it is likely that concentrations greater than the maximum MIC for penicillin of the current isolates would be achieved. Following infusion of 1 million international units (i.e. approximately $606 \mathrm{mg}$ ) of penicillin $\mathrm{G}$ on 3 occasions at 12 hourly intervals, the mean milk concentration of penicillin was $175 \mathrm{mg} / \mathrm{L}$ (Moretain and Boisseau, 1989), approximately 700-fold higher than the $\mathrm{MIC}_{50}$ for penicillin found amongst the $\mathrm{E}_{381} \mathrm{~K}$ substitute isolates in the current study. The $\mathrm{E}_{381} \mathrm{~K}, \mathrm{Q}_{554} \mathrm{E}$, and $\mathrm{G}_{600} \mathrm{E}$ substitutions were associated with increased MIC for all $\beta$-lactams tested, other than cephalexin. Similarly, there was a positive association between the MIC for oxacillin and all other $\beta$-lactams, other than cefalexin. Different effects on sensitivity within antimicrobials class within mutations to $p b p 2 x$ have been previously described. Laboratory $p b p 2 x$ mutants which increased cefotaxime MIC by more than 10 fold had no effect, or increased, sensitivity to oxacillin (Grebe and Hakenbeck, 1996).

\subsection{Population structure}

The current study found multiple MLST types including many novel types. In common with a number of previous studies, it is clear that bovine mammary S. uberis are a highly diverse population (Davies et al., 2016; Zadoks et al., 2011). There was limited evidence of clonal expansion within or between dairy herds in New Zealand, suggesting a predominantly environmental source of S. uberis in the New Zealand context, as distinct from cow to cow transmission inferred from some previous studies (Davies et al., 2016; Zadoks et al., 2011).

Streptococci are generally found to be recombinogenic as seen in S. pneumoniae (Croucher et al., 2014). This leads to substantial genome modification likely via a 
combination of point mutations, homologous recombination and movement of mobile genetic

347 elements (Croucher et al., 2014). This suggests that the association between the increased

MIC for oxacillin and the $p b p 2 x$ genotype is more likely to be causal and not just a result of

349 clonal expansion of lineages carrying the $p b p 2 x$ substitutions contained in a resistant

350 background genome. The Gubbins analysis indicated that recombination events are particularly common in S. uberis. This places constraints on the interpretation of any phylogeny within this species not taking recombination into account although it should be noted that the maximum likelihood tree from the core genome shared much of the same structure as the tree from the Gubbins analysis (which accounted for recombination). As might be expected, the $p b p 2 x \mathrm{E}_{381} \mathrm{~K}, \mathrm{Q}_{554} \mathrm{E}$, and $\mathrm{G}_{600} \mathrm{E}$ substitutions were conserved amongst closely related isolates using the core genome phylogeny. However, there were many examples of isolates within the same clade having different $p b p 2 x$ genotypes suggesting multiple $p b p 2 x$ mutation or acquisition events.

\subsection{GWAS}

The GWAS independently identified the $p b p 2 x$ locus. Additionally, the $m r a Y$ locus was identified which codes for phospho-N-acetylmuramoyl-pentapeptide-transferase, an enzyme responsible for the formation of the first lipid intermediate of the cell wall peptidoglycan synthesis. These two loci were also identified in a GWAS study of $S$. pneumoniae (Chewapreecha et al., 2014). Two loci not previously reported as being associated with $\beta$ lactam resistance in Streptococci were identified including yxe $M$ which codes for an extracellular solute-binding protein and yxeN which codes for an $\mathrm{ABC}$ transporter permease. These later 2 genes flank $p b p 2 x$, and it is likely that they are associated due to linkage disequilibrium. Interestingly $\operatorname{csh} B$, which codes for a surface associated protein, and is located between mraY and yxeN, contained a number of SNPs, none of which were associated with oxacillin resistance. The reason for this is unclear; all isolates possessed this gene, and 
in the same location. A number of loci identified in the GWAS of S. pneumoniae

(Chewapreecha et al., 2014) including $c l p L, c i a H, f t s L$ and gpsB were not associated with $\beta$ lactam resistance in the current study.

\subsection{Cure rate}

As the original intervention studies were not powered to specifically test the effect of $E_{381} K, Q_{554} E$, and $G_{600} E$ substitutions on bacteriological cure rate, care should be taken when interpreting the cure rate data given the relatively small sample size.

However, numerically the cure rate was lower amongst $S$. uberis isolates with the $\mathrm{E}_{381} \mathrm{~K}$, $\mathrm{Q}_{554} \mathrm{E}$, and $\mathrm{G}_{600} \mathrm{E}$ substitutions than those without these substitutions. The cure rate was numerically lower for isolates with $\mathrm{E}_{381} \mathrm{~K}, \mathrm{Q}_{554} \mathrm{E}$, and $\mathrm{G}_{600} \mathrm{E}$ substitutions following treatment with a $\beta$-lactam compared with a non- $\beta$-lactam. This is biologically plausible as the SNP in the $p b p 2 x$ is only likely to affect $\beta$-lactams, and not the efficacy of antimicrobials operating via different mechanisms. Increasing the duration of therapy with a $\beta$-lactam to $5 \times 12$ hourly tended to overcome the depression in cure rate seen with a shorter duration of therapy (i.e. the $3 \times 12$ hourly treatment). Again, this is biologically plausible given that $\beta$-lactams are timedependent antimicrobials, hence with increasing duration it is feasible that concentrations above MIC were of sufficiently long duration to result in bacteriological cure even amongst isolates with increasing MIC. Failure to detect difference in cure rate between $p b p 2 x$ genotypes could also have been due to presence of other resistance mechanisms being present masking any effect of the $p b p 2 x$ genotype. For example, in the first study the control group was treated with a combination of an aminoglycoside, a macrolide and a tetracycline. While streptococci are considered to constitutively resistant to aminoglycosides (Jayarao and Oliver, 1992), there was no evidence of tetracycline resistance genes in the current study, and only 7 isolates had presence of the ermB gene conferring increased MIC to macrolides (unpublished 

cloxacillin MIC. However, this hypothesis remains to be tested. multiple independent SNPs have occurred over time.

Presence of the $\mathrm{E}_{381} \mathrm{~K}, \mathrm{Q}_{554} \mathrm{E}$, and $\mathrm{G}_{600} \mathrm{E}$ substitutions was numerically associated with

417 lower bacteriological cure rates following treatment with a $\beta$-lactam compared with a non- $\beta$ -

data). Thus, it is considered unlikely that the failure to differentiate cure rate was due to a reduced cure rate in the non- $\beta$-lactam treatment group.

The maximum MIC for cloxacillin of any isolates in the current study was $2 \mathrm{mg} / \mathrm{L}$.

Ongoing monitoring of the MIC of $S$. uberis isolates, and the association between MIC and clinical and bacteriological cure rates amongst clinical mastitis cases associated with $S$. uberis is required. Additionally, as cloxacillin-based antimicrobials are the most commonly used at the end of lactation (i.e. for dry-cow therapy), it is plausible that ongoing use of antimicrobials at the end of lactation may result in selection of $S$. uberis with higher

\section{Conclusions}

This study has found widespread evidence for increased MIC of oxacillin amongst the common bovine mastitis pathogen S. uberis. The great majority of isolates with an increased MIC for oxacillin were found to have substitutions in $p b p 2 x$, and the $\mathrm{E}_{381} \mathrm{~K}, \mathrm{Q}_{554} \mathrm{E}$, and $\mathrm{G}_{600} \mathrm{E}$ substitutions were predictive of the increased MIC for oxacillin phenotype and did not require inclusion of substitutions on other $p b p$ in the final predictive models. Isolates with the $\mathrm{E}_{381} \mathrm{~K}, \mathrm{Q}_{554} \mathrm{E}$, and $\mathrm{G}_{600} \mathrm{E}$ substitutions were also found in Canadian, European and UK isolates, suggesting wide geographic distribution of this genotype. Phylogenetic analysis found the $\mathrm{E}_{381} \mathrm{~K}, \mathrm{Q}_{554} \mathrm{E}$, and $\mathrm{G}_{600} \mathrm{E}$ substitutions were widely distributed amongst New Zealand clades, but there was variation in $p b p 2 x$ genotype within closely related isolates. This suggests that horizontal gene transfer may be occurring, as has been reported in other Streptococci, or that 


\section{Acknowledgements}

The provision of some isolates by Estendart Ltd is gratefully acknowledged.

\section{Funding}

Funding for the original intervention studies from which the isolates were obtained was 424 provided by Zoetis Animal Health, and Virbac New Zealand Limited. These funding bodies 425 played no role in the design, analysis and reporting of the current study. The current research 426 did not receive any specific grant from funding agencies in the public, commercial, or not427 for-profit sectors.

\section{Transparency declarations}

The authors declare that they have no competing interests.

LC, IG, and HJH undertook the original microbiology to isolate and confirm the 431 phenotypic identity of the $S$. uberis and initial MIC determination. NH, EL, XR and XB 432 undertook DNA sequence preparation and final MIC determinations. OR developed the 433 mixture models. JP contributed to manuscript reparation. MB undertook one of the 434 intervention studies. MH managed the sequencing processing, and contributed to the study 435 design, analysis and interpretation. SM undertook the design, analysis, interpretation and 436 manuscript preparation. All authors read and approved the final manuscript. 


\section{Availability of data and materials statement}

The assemblies of the isolates are in the European Nucleotide Archive

439 (https://www.ebi.ac.uk/ena).

440 Additional phenotypic data (New Zealand Island location, oxacillin MIC) and genotype 441 data $\left(p b p 2 x \mathrm{E}_{381} \mathrm{~K}\right.$ as $\left.0 / 1\right)$ is included in Supplementary Table 1.

\section{10. References}

443 Barsh, G.S., Copenhaver, G.P., Gibson, G., Williams, S.M., 2012. Guidelines for genome$444 \quad$ wide association studies. PLoS Genetics 8, e1002812.

445 Bradley, A.J., Leach, K.A., Breen, J.E., Green, L.E., Green, M.J., 2007. Survey of the 446 incidence and aetiology of mastitis on dairy farms in England and Wales. Vet. Rec. 160, 447 $253-258$.

Bryan, M.A., Hea, S.Y., Mannering, S.A., Booker, R., 2016. Demonstration of noninferiority of a novel combination intramammary antimicrobial in the treatment of clinical mastitis. N. Z. Vet. J. 64, 337-342.

451 Carapito, R., Chesnel, L., Vernet, T., Zapun, A., 2006. Pneumococcal beta-lactam resistance due to a conformational change in penicillin-binding protein 2x. J. Biol. Chem. 281, 1771-

454 Chewapreecha, C., Marttinen, P., Croucher, N.J., Salter, S.J., Harris, S.R., Mather, A.E., 455 Hanage, W.P., Goldblatt, D., Nosten, F.H., Turner, C., Turner, P., Bentley, S.D., Parkhill, 456 J., 2014. Comprehensive identification of single nucleotide polymorphisms associated 
CLSI 2013. Performance standards for antimicrobial disk and dilution susceptibility tests for 460 bacteria isolated from animals; Approved standard- fourth edition. CLSI document 461 VET01-A4 (Wayne, PA., USA, Clinical and Laboratory Standards Institute).

462 Coffey, T.J., Pullinger, G.D., Urwin, R., Jolley, K.A., Wilson, S.M., Maiden, M.C., Leigh, J.A., 2006. First insights into the evolution of Streptococcus uberis: a multilocus sequence typing scheme that enables investigation of its population biology. Appl. Environ. Microbiol. 72, 1420-1428.

471 Croucher, N.J., Hanage, W.P., Harris, S.R., McGee, L., van der Linden, M., de Lencastre, H.,

Connor, T.R., Loman, N.J., Thompson, S., Smith, A., Southgate, J., Poplawski, R., Bull, M.J., Richardson, E., Ismail, M., Thompson, S.E.-., Kitchen, C., Guest, M., Bakke, M., Sheppard, S.K., Pallen, M.J., 2016. CLIMB (the Cloud Infrastructure for Microbial Bioinformatics): an online resource for the medical microbiology community. Microbial Genomics 2, e000086. 
479 Davies, P.L., Leigh, J.A., Bradley, A.J., Archer, S.C., Emes, R.D., Green, M.J., 2016.

480 Molecular epidemiology of Streptococcus uberis clinical mastitis in dairy herds: Strain

481 heterogeneity and transmission. J. Clin. Microbiol. 54, 68-74.

482 Dowson, C.G., Coffey, T.J., Spratt, B.G., 1994. Origin and molecular epidemiology of 483 penicillin-binding-protein-mediated resistance to beta-lactam antibiotics. Trends $484 \quad$ Microbiol. 2, 361-366.

Du Plessis, M., Bingen, E., Klugman, K.P., 2002. Analysis of penicillin-binding protein genes of clinical isolates of Streptococcus pneumoniae with reduced susceptibility to amoxicillin. Antimicrob. Agents Ch. 46, 2349-2357.

488 Everitt, B.S., 1996. An introduction to finite mixture distributions. Stat. Methods Med. Res. $489 \quad 52,2107-2127$.

490 Garau, J., 2002. Treatment of drug-resistant pneumococcal pneumonia. Lancet Infect. Dis. 2, $491 \quad 404-415$.

492 Grebe, T., Hakenbeck, R., 1996. Penicillin-binding proteins $2 \mathrm{~b}$ and 2x of Streptococcus 493 pneumoniae are primary resistance determinants for different classes of b-lactam 494 antibiotics. Antimicrob. Agents Ch. 40, 829-834.

495 Guérin-Faublée, V., Carret, G., Houffschmitt, P., 2003. In vitro activity of 10 antimicrobial 496 agents against bacteria isolated from cows with clinical mastitis. Vet. Rec. 152, 466-471.

497 Hadfield, J., Croucher, N.J., Goater, R.J., Abudahab, K., Aanensen, D.M., Harris, S.R., 2017. 498 Phandango: an interactive viewer for bacterial population genomics. Bioinformatics 34, $499 \quad 292-293$. 
Haenni, M., Galofaro, L., Ythier, M., Giddey, M., Majcherczyk, P., Moreillon, P., Madec, J.-

Haenni, M., Lupo, A., Madec, J.Y., 2018. Antimicrobial Resistance in Streptococcus spp. Microbiol. Spectr. 6, 25.

Hakenbeck, R., Bruckner, R., Denapaite, D., Maurer, P., 2012a. Molecular mechanisms of beta-lactam resistance in Streptococcus pneumoniae. Future Microbiol. 7, 395-410.

513 Hakenbeck, R., Grebe, T., Zähner, D., Stock, J.B., 1999. beta-lactam resistance in

Hakenbeck, R., Brückner, R., Denapaite, D., Maurer, P., 2012b. Molecular mechanisms of ßlactam resistance in Streptococcus pneumoniae. Future Microbiol. 7, 395-410.

516 Hossain, M., Egan, S.A., Coffey, T., Ward, P.N., Wilson, R., Leigh, J.A., Emes, R.D., 2015.

517 Virulence related sequences; insights provided by comparative genomics of Streptococcus 518 uberis of differing virulence. BMC Genomics 16, 1-13.

519 Jayarao, B.M., Oliver, S.P., 1992. Aminoglycoside-resistant Streptococcus and Enterococcus species isolated from bovine mammary secretions. J. Dairy Sci. 75, 991-997. 
521 Lang, P., Lefébure, T., Wang, W., Zadoks, R.N., Schukken, Y., Stanhope, M.J., 2009. Gene content differences across strains of Streptococcus uberis identified using oligonucleotide microarray comparative genomic hybridization. Infect. Genet. Evol. 9, 179-188.

524 Lees, J.A., Vehkala, M., Välimäki, N., Harris, S.R., Chewapreecha, C., Croucher, N.J., 525 Marttinen, P., Davies, M.R., Steer, A.C., Tong, S.Y.C., Honkela, A., Parkhill, J., Bentley, S.D., Corander, J., 2016. Sequence element enrichment analysis to determine the genetic

Letunic, I., Bork, P., 2016. Interactive Tree Of Life (iTOL) v3: an online tool for the display and annotation of phylogenetic and other trees. Nucleic Acids Res. 44 (W1), W242W245.

McDougall, S., 1998. Efficacy of two antibiotic treatments in curing clinical and subclinical mastitis in lactating dairy cows. N. Z. Vet. J. 46, 226-232.

McDougall, S., Arthur, D.G., Bryan, M.A., Vermunt, J.J., Weir, A.M., 2007a. Clinical and bacteriological response to treatment of clinical mastitis with one of three intramammary antibiotics. N. Z. Vet J. 55, 161-170.

McDougall, S., Arthur, D.G., Bryan, M.A., Vermunt, J.J., Weir, A.M., 2007b. Clinical and bacteriological response to treatment of clinical mastitis with one of three intramammary antibiotics. New Zealand Veterinary Journal 55, 161-170.

McDougall, S., Clausen, L., Hintukainen, J., Hunnam, J., 2019. Randomized, controlled, superiority study of extended duration of therapy with an intramammary antibiotic for treatment of clinical mastitis. J. Dairy Sci. 102, 4376-4386. 
542 McDougall, S., Hussein, H., Petrovski, K., 2014. Antimicrobial resistance in Staphylococcus

543 aureus, Streptococcus uberis and Streptococcus dysgalactiae from dairy cows with

544 mastitis. N. Z. Vet J. 62, 68-76.

545 Moretain, J.P., Boisseau, J., 1989. Excretion of penicillins and cephalexin in bovine milk 546 following intramammary administration. Food Addit. Contam. 6, 79-89.

547 Nagai, K., Davies, T.A., Jacobs, M.R., Appelbaum, P.C., 2002. Effects of amino acid 548 alterations in penicillin-binding proteins (PBPs) 1a, 2b, and 2x on PBP affinities of 549 penicillin, ampicillin, amoxicillin, cefditoren, cefuroxime, cefprozil, and cefaclor in 18 550 clinical isolates of penicillin-susceptible, -intermediate, and -resistant pneumococci. $551 \quad$ Antimicrob. Agents Ch. 46, 1273-1280.

552 Ondov, B.D., Treangen, T.J., Melsted, P., Mallonee, A.B., Bergman, N.H., Koren, S., 553 Phillippy, A.M., 2016. Mash: fast genome and metagenome distance estimation using $554 \quad$ MinHash. Genome Biology 17, 132.

555 Owens, W.E., Ray, C.H., Watts, J.L., Yancey, R.J., 1997. Comparison of success of antibiotic 556 therapy during lactation and results of antimicrobial susceptibility tests for bovine mastitis.

558 Page, A.J., Cummins, C.A., Hunt, M., Wong, V.K., Reuter, S., Holden, M.T.G., Fookes, M., 559 Falush, D., Keane, J.A., Parkhill, J., 2015. Roary: Rapid large-scale prokaryote pan 560 genome analysis. Bioinformatics 31, 3691-3693.

561 Page, A.J., De Silva, N., Hunt, M., Quail, M.A., Parkhill, J., Harris, S.R., Otto, T.D., Keane, 562 J.A., 2016. Robust high-throughput prokaryote de novo assembly and improvement 563 pipeline for Illumina data. Microb. Genom. 25, e000083. 
564 Peters, K., Pipo, J., Schweizer, I., Hakenbeck, R., Denapaite, D., 2016. Promoter identification and transcription analysis of penicillin-binding protein genes in Streptococcus pneumoniae R6. Microb. Drug. Resis. 22, 487-498.

Phuektes, P., Mansell, P.D., Dyson, R.S., Hooper, N.D., Dick, J.S., Browning, G.F., 2001. Molecular epidemiology of Streptococcus uberis isolates from dairy cows with mastitis. J. Clin. Microbiol. 39, 1460-1466.

Pullinger, G.D., Lopez-Benavides, M., Coffey, T.J., Williamson, J.H., Cursons, R.T., Summers, E., Lacy-Hulbert, J., Maiden, M.C., Leigh, J.A., 2006. Application of Streptococcus uberis multilocus sequence typing: Analysis of the population structure detected among environmental and bovine isolates from New Zealand and the United Kingdom. Appl. Environ. Microbiol. 72, 1429-1436.

Quail, M.A., Kozarewa, I., Smith, F., Scally, A., Stephens, P.J., Durbin, R., Swerdlow, H., Turner, D.J., 2008. A large genome center's improvements to the Illumina sequencing system. Nat. Methods 5, 1005-1010.

Sandholm, M., Kaartinen, L., Pyorala, S., 1990. Bovine mastitis - why does therapy not always work? An overview. J. Vet. Pharmacol. Ther. 13, 248-260.

Smith, A.M., Klugman, K.P., 1998. Alterations in PBP 1A essential-for high-level penicillin resistance in Streptococcus pneumoniae. Antimicrob. Agents Ch. 42, 1329-1333.

Smith, A.M., Klugman, K.P., 2005. Amino acid mutations essential to production of an altered PBP 2x conferring high-level beta-lactam resistance in a clinical isolate of Streptococcus pneumoniae. Antimicrob. Agents Ch. 49, 4622-4627. 
Stamatakis, A., 2014. RAxML Version 8: A tool for phylogenetic analysis and post-analysis 586 of large phylogenies. Bioinformatics 30, 1312-1313.

587 Tenhagen, B., Köster, G., Wallman, J., Heuwieser, W., 2006. Prevalence of mastitis

588 pathogens and their resistance against antimicrobial agents in dairy cows in Brandenburg, 589 Germany. J. Dairy Sci. 89, 2542-2551.

590 Vélez, J.R., Cameron, M., Rodriguez-Lecompte, J.C., Xia, F., Heider, L.C., Saab, M., 591 McClure, J.T., Sanchez, J., 2017. Whole-genome sequence analysis of antimicrobial 592 resistance genes in Streptococcus uberis and Streptococcus dysgalactiae isolates from 593 Canadian dairy herds. Front. Vet. Sci. 4, 1-11.

594 Zadoks, R.N., Gillespie, B.E., Barkema, H.W., Sampimon, O.C., Oliver, S.P., Schukken, 595 Y.H., 2003. Clinical, epidemiological and molecular characteristics of Streptococcus 596 uberis infections in dairy herds. Epidemiology \& Infection 130, 335-349.

597 Zadoks, R.N., Middleton, J.R., McDougall, S., Katholm, J., Schukken, Y.H., 2011. Molecular 598 epidemiology of mastitis pathogens of dairy cattle and comparative relevance to humans. $599 \quad$ Journal of Mammary Gland Biology and Neoplasia 16, 357-372.

600 Zapun, A., Contreras-Martel, C., Vernet, T., 2008. Penicillin-binding proteins and ß-lactam 601 resistance. FEMS Microbiol. Rev. 32, 361-385 
Table 1

603 Penicillin binding protein (PBP) number, residue number (based on previously reported

604 (Haenni et al., 2010b) numbering for pbpla, $2 b$ and $2 x$, otherwise from the start of the open

605 reading frame), most common residue at that position (core residue), the number of isolates

606 with the core residue at that position, the amino acid of the variant and the number of isolates

607 with this variant, the P-value from chi squared analysis of the variant against the isolate being

608 resistant (that is, an oxacillin MIC of $>0.5 \mathrm{mg} / \mathrm{L}$ ), and the number and percentage of isolates

609 in core and variant amino acids with oxacillin resistance. Note only those substitutions with

$610>10 \%$ prevalence and within the transpeptidase domain (for $p b p 1 a, 2 b$ and $2 x$ ) are listed.

611 Where the same substitutions were identified in Canadian (Vélez et al., 2017) and UK

612 (Hossain et al., 2015) isolates these are listed.

\section{Table 2}

614 The mean, standard error of the mean (SEM) and median minimum inhibitory concentration

$615\left(\mathrm{MIC}_{50} ; \mathrm{mg} / \mathrm{mL}\right)$ for $\beta$-lactam antimicrobials for Streptococcus uberis isolates with and

616 without the $\mathrm{E}_{381} \mathrm{~K}$ substitution in $p b p 2 x$. 
617 Fig. 1. Frequency histogram of minimum inhibitory concentrations $(\mathrm{mg} / \mathrm{L})$ of oxacillin for 618 Streptococcus uberis from bovine clinical mastitis cases.

619 Fig. 2 a, b, c. Sites in (a) $p b p 1 a$, (b) $p b p 2 b$, and (c) $p b p 2 x$ implicated in altered affinity to $\beta$ 620 lactams. The transpeptidase domain is represented as the horizontal black bar; the active site 621 motifs are indicated in blue and marked by blue triangles. Numbers in brackets indicate the position of the first and last amino acids of the transpeptidase domain. The substitutions in 623 green are from the current study, and the red substitutions are from those induced in S. uberis 624 (Haenni et al., 2010a). Note only substitutions present in $>10 \%$ of isolates in the current 625 study are represented.

626 Fig. 3. Box plots of the MIC of $\beta$-lactams for S. uberis isolates from bovine clinical mastitis 627 cases defined as oxacillin resistant (i.e. MIC $\geq 0.5 \mathrm{mg} / \mathrm{L})$ or susceptible $(<0.5 \mathrm{mg} / \mathrm{L})$.

628 Fig. 4 a,b. Estimated marginal mean (95\% confidence intervals) for cure proportion for (a) study 1 for quarters infected with $S$. uberis that had the $\mathrm{E}_{381} \mathrm{~K}$ substitution (open bar) or not 630 (solid bar) by treatment type. The non- $\beta$-lactam treatment was daily intramammary infusion 631 for 3 days of a combination of $200 \mathrm{mg}$ oxytetracycline, $100 \mathrm{mg}$ oleandomycin, $100 \mathrm{mg}$ 632 neomycin and $5 \mathrm{mg}$ prednisolone, and $\beta$-lactam treatment was daily infusion 3 days of a 633 combination of $1 \mathrm{~g}$ penicillin and $200 \mathrm{mg}$ cloxacillin, and (b) cure proportion for quarters 634 treated by intramammary infusion at 12 hourly intervals with $200 \mathrm{mg}$ amoxycillin, $50 \mathrm{mg}$ clavulanic acid, and $10 \mathrm{mg}$ prednisolone on three (hatched bar) or five (open bar) occasions. 
636 Supplementary Table 1. Isolate identity, multilocus sequence type (Sequence type),

637 oxacillin minimum inhibitory concentration $(\mathrm{Ox}$ MIC $(\mathrm{mg} / \mathrm{L}))$, resistance phenotype

638 (resistant $(1)=\geq 0.5 \mathrm{mg} / \mathrm{L})$, resistance genotype $\left(1=p b p 2 x \mathrm{E}_{381} \mathrm{~K}\right.$ substitution), location in

639 New Zealand (North or South Island) and the unique farm identity (Farm_ID), ENA sample 640 accession number, and ENA lane accession number. 
641 Supplementary Fig. 1. Phylogenetic tree of 265 S. uberis isolates from bovine clinical

642 mastitis cases in New Zealand (classified as from the North or South Island) and S. uberis

643 isolates from Canada and the UK. The tree is created from the core genome $(\sim 1,500$ genes $)$ of

644 S. uberis. The meta data includes (from inner to outer) isolate number, multilocus sequence

645 type, island of New Zealand, farm identity, $p b p 2 x \mathrm{E}_{381} \mathrm{~K}$ genotype (open green Square = wild

646 (sensitive) genotype; closed green square = resistant genotype), and oxacillin MIC phenotype

647 (red open square $<0.5 \mathrm{mg} / \mathrm{L}$, closed red square $\geq 0.5 \mathrm{mg} / \mathrm{L})$.

648 Supplementary Fig. 2. Manhattan plot showing the results of a k-mer based genome wide 649 association study using SEER visualised using Phandango. The reference genome used was 650 17652_8\#12.gff. The annotation file was generated by Prokka as part of the Welcome Sanger 651 Institute Pathogen Informatics pipeline. The size of the dots indicates the length of positively 652 associated k-mer. A threshold of $\mathrm{P}<5 \times 10^{-8}$ was applied. The vertical axis is the negative of 653 the $\log 10$ value of $\mathrm{P}$. The horizontal axis represents the base pair distance along the genome.

654 Supplementary Fig. 3. Gubbins plot of 265 S. uberis isolates from bovine clinical mastitis 655 cases in New Zealand. The phylogenetic tree (left panel) represents the maximum likelihood 656 tree. The $S$. uberis $0140 \mathrm{~J}$ genome is represented as the blue vertical bars across the top of the 657 figure, while the vertical red bars in the centre of the figure represent the density estimates of 658 recombination events. The line graph at the bottom of the figure is the cumulative frequency 659 of recombination events at that locus. 


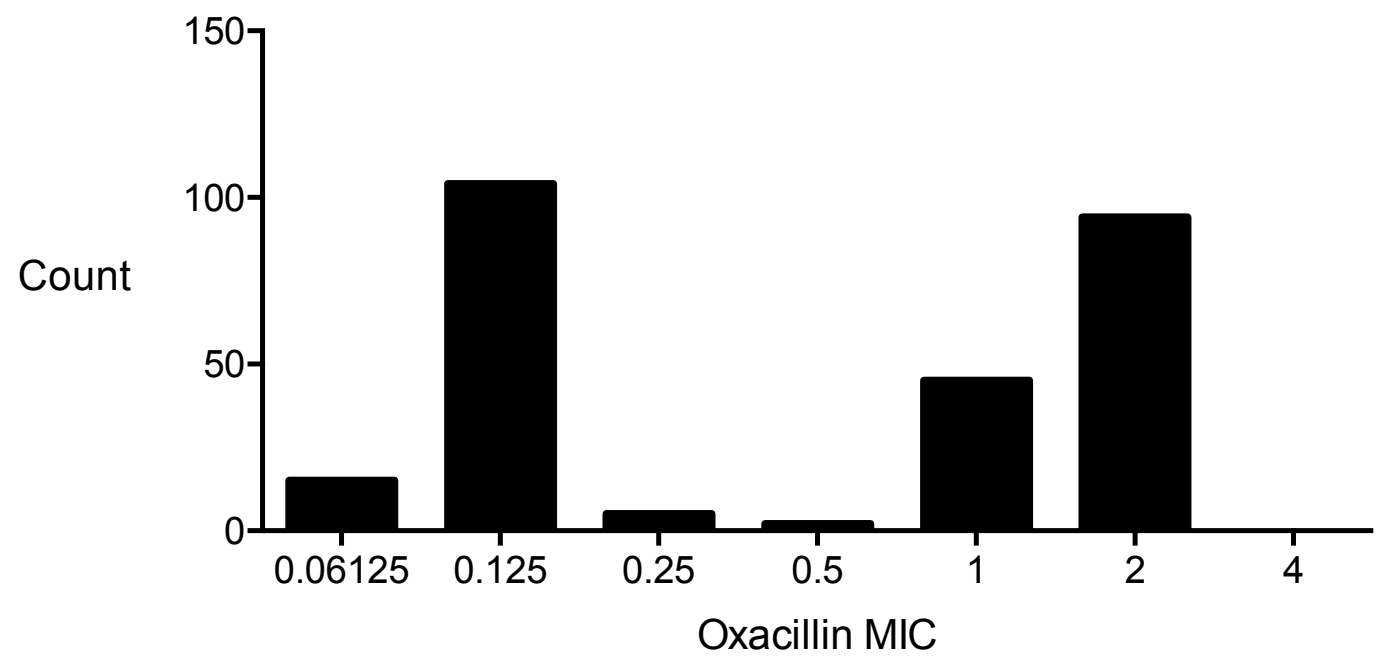


(a)

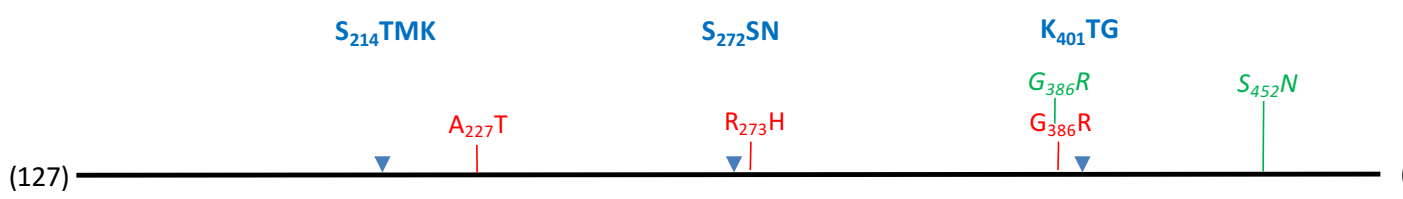

(b)

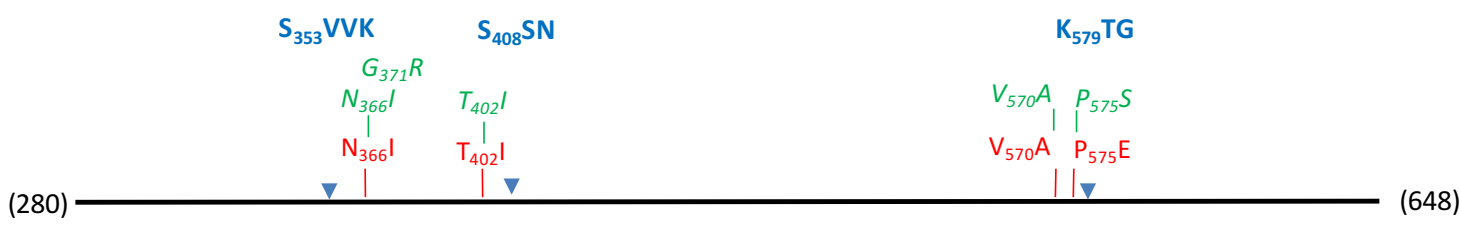

(c)

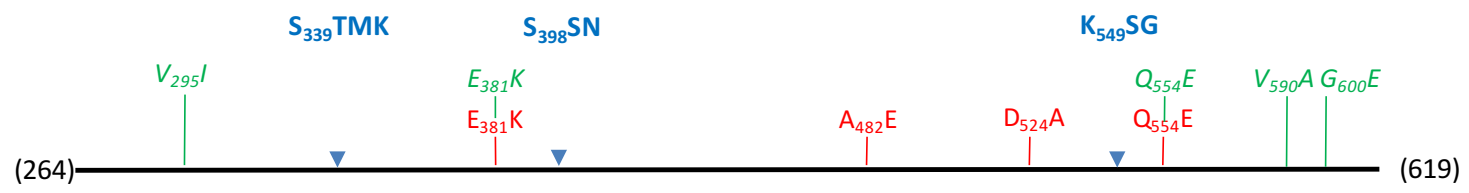




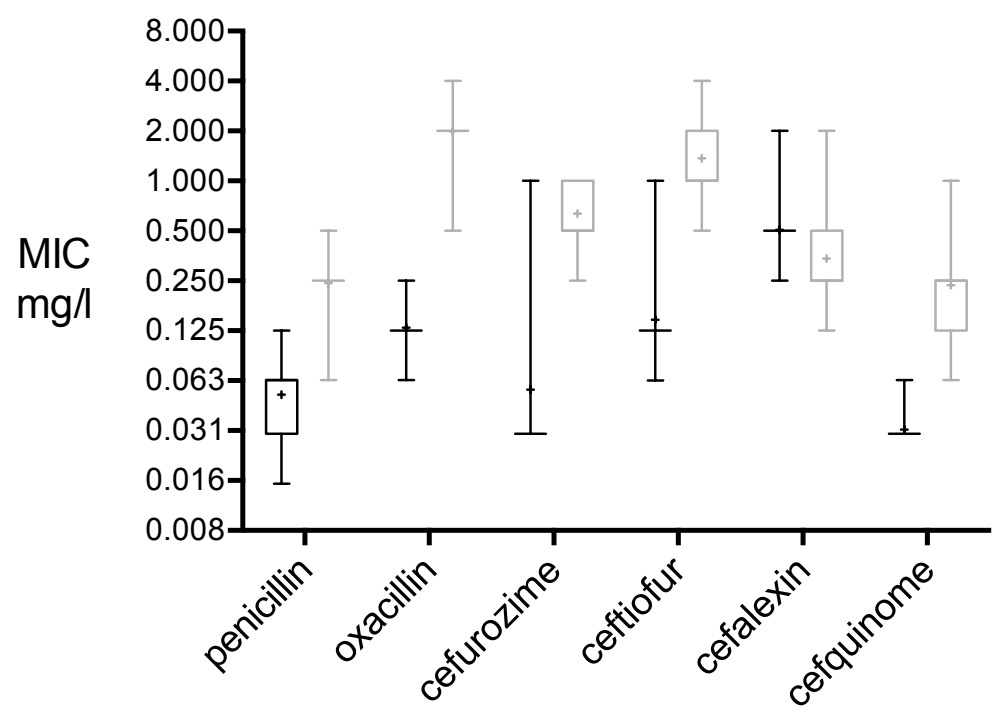

$\square$ Susceptible

$\square$ Resistant 


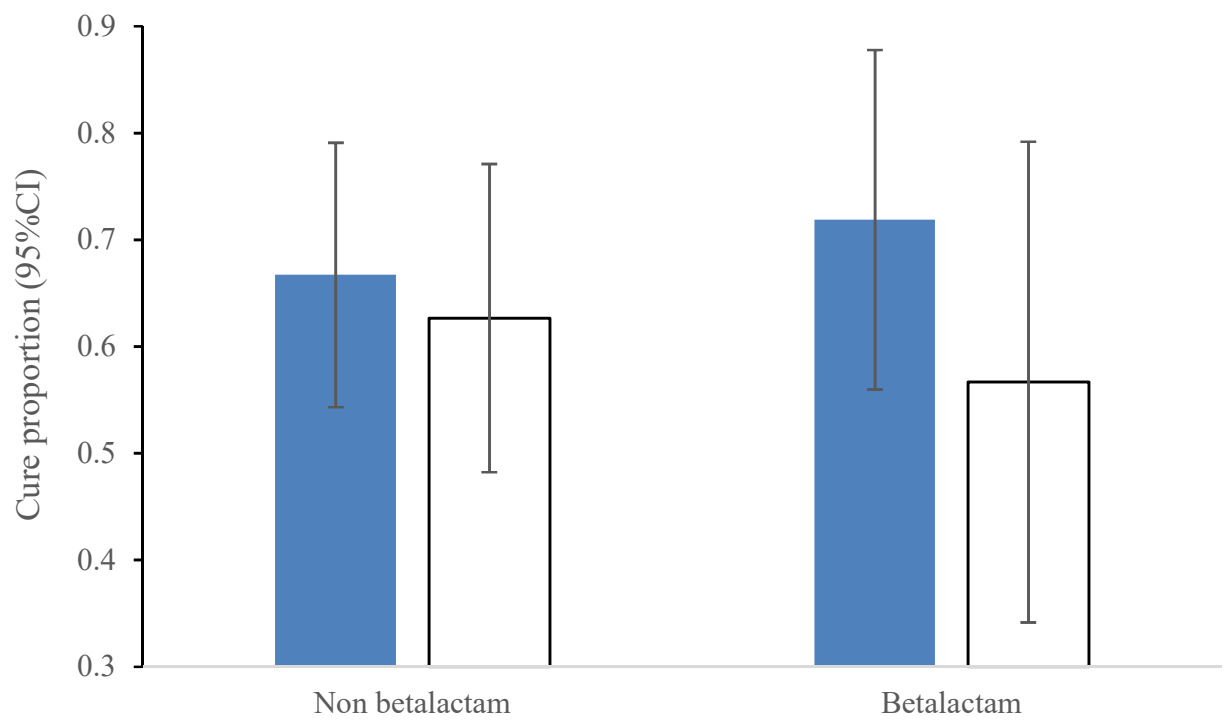




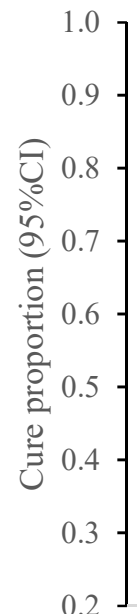
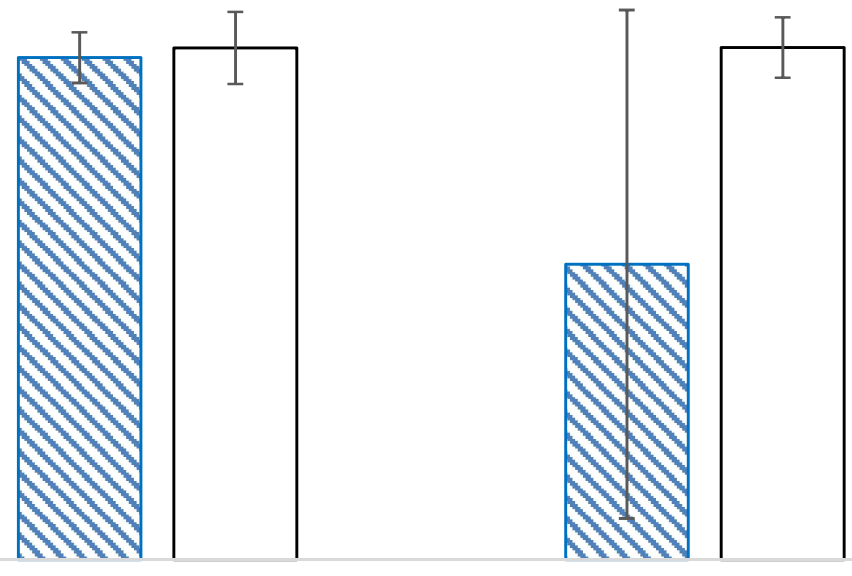

PBP 2x E381K genotype 


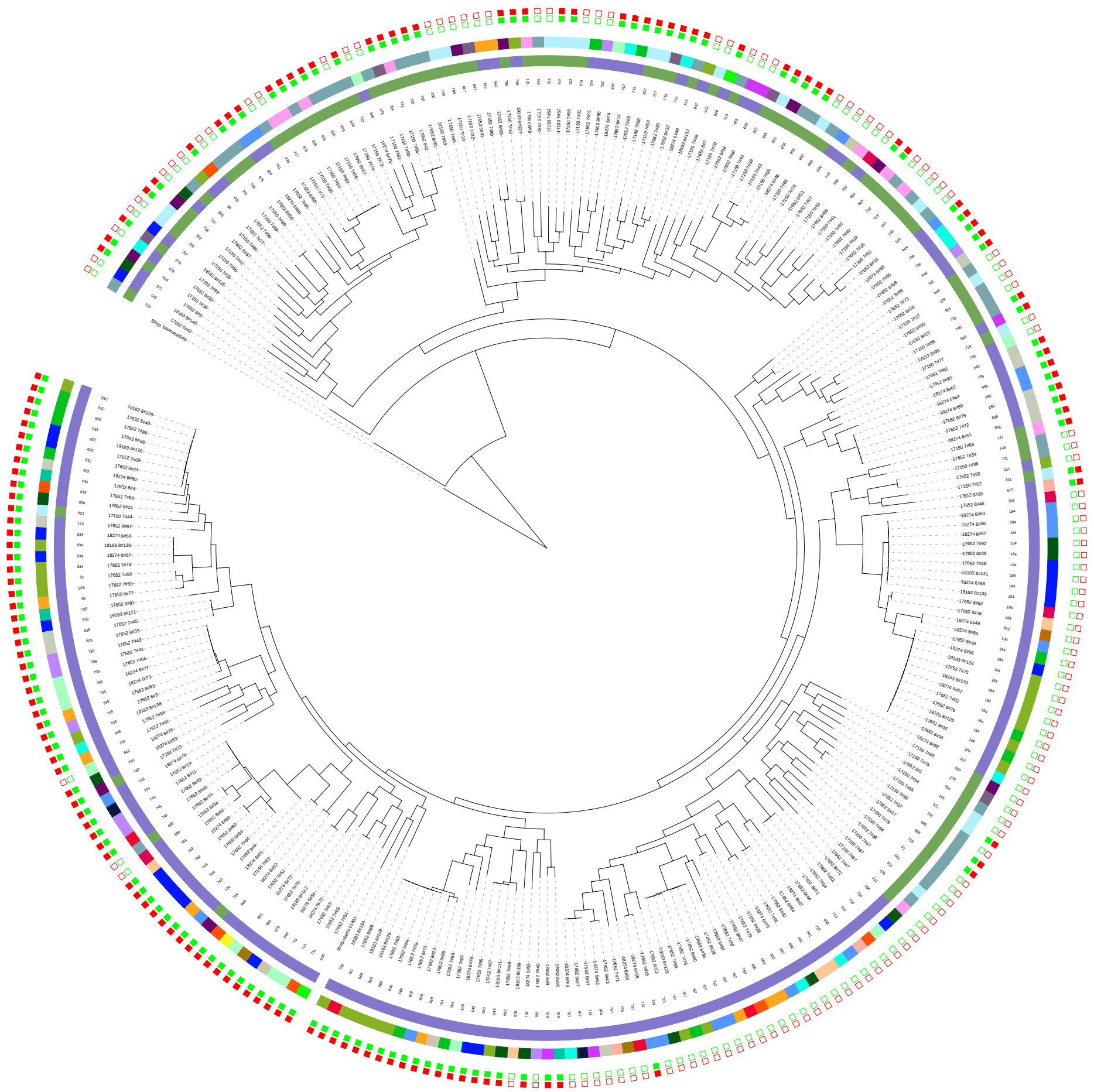




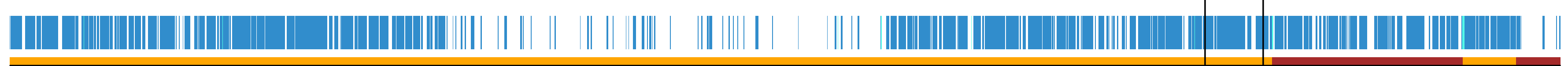

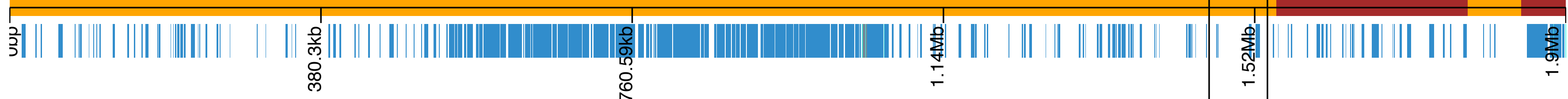

12
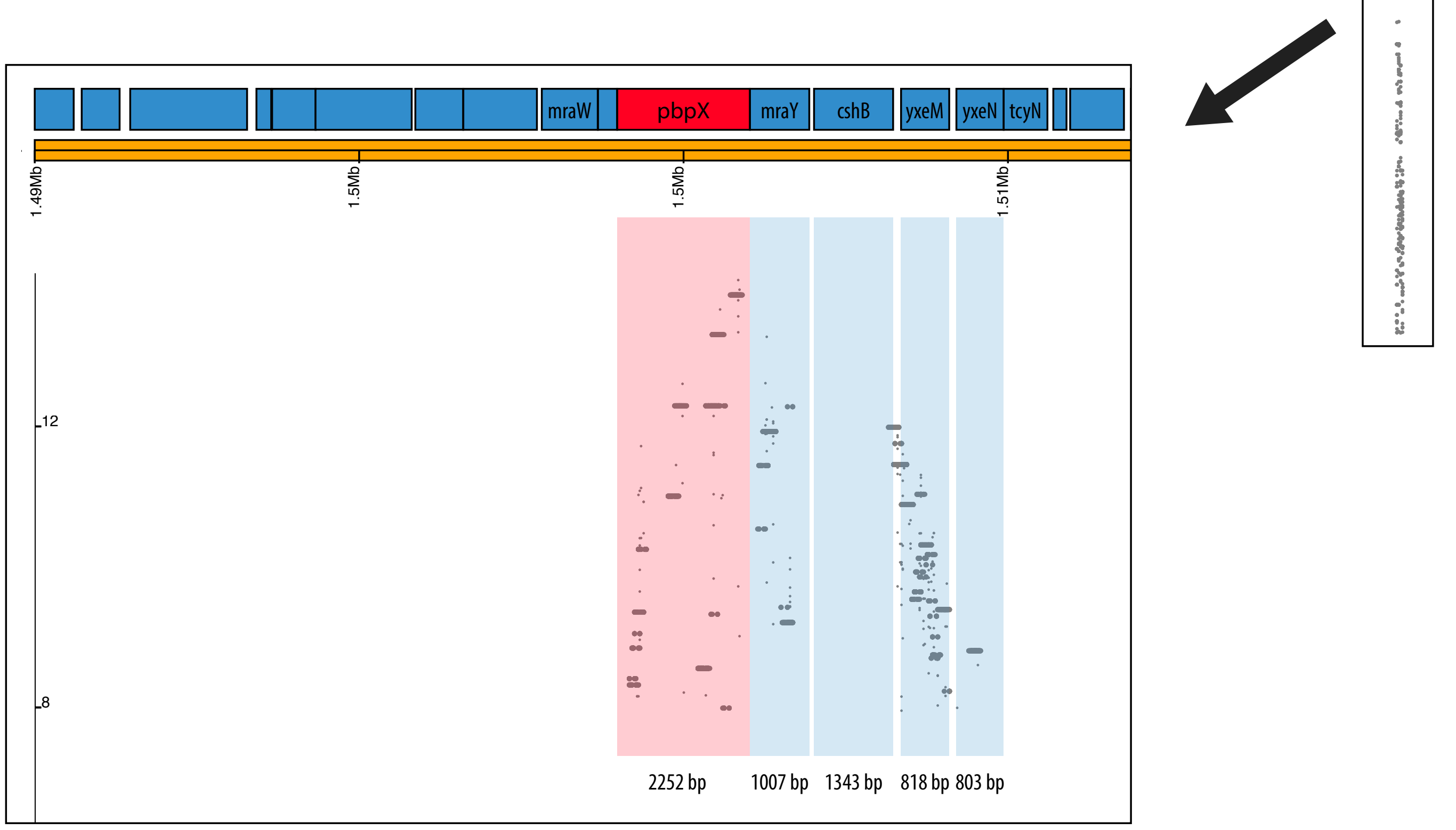

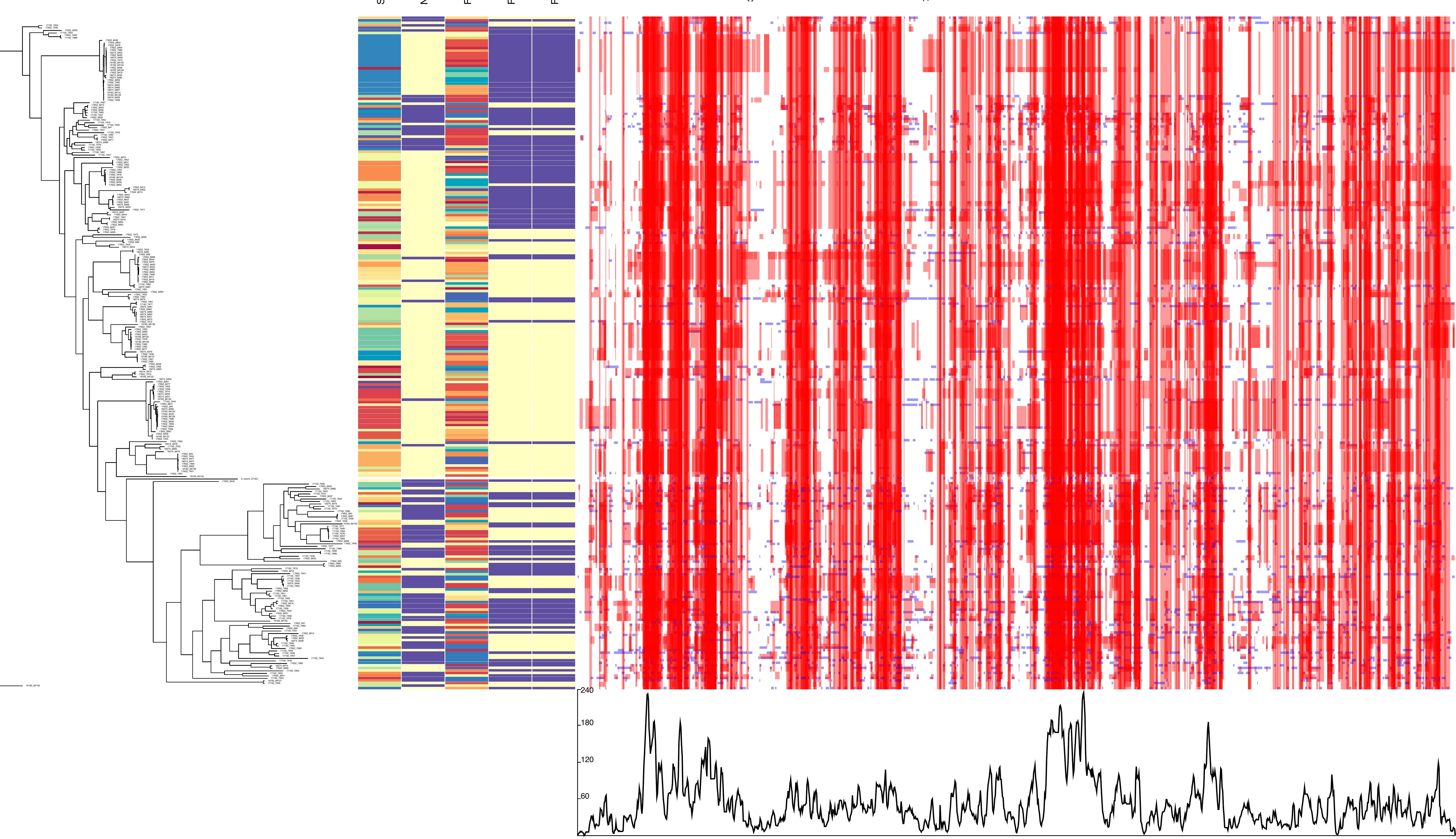


\section{Table 1}

Penicillin binding protein number (PBP), residue number (based on previously reported (Haenni et al., 2010b) numbering for $p b p 1 a, 2 b$ and $2 x$, otherwise from the start of the open reading frame), most common residue at that position (core residue), the number of isolates with the core residue at that position, the amino acid of the variant and the number of isolates with this variant, the P-value from chi squared analysis of the variant against the isolate being resistant (that is oxacillin MIC of $>0.5 \mathrm{mg} / \mathrm{L}$ ), and the number and percentage of isolates in core and variant amino acids with oxacillin resistance. Note only those substitutions with $>10 \%$ prevalence and within the transpeptidase domain (for PBP1a, $2 \mathrm{~b}$ and $2 \mathrm{x}$ ) are listed. Where the same substitutions were identified in Canadian (Vélez et al., 2017) and UK (Hossain et al., 2015) isolates these are listed.

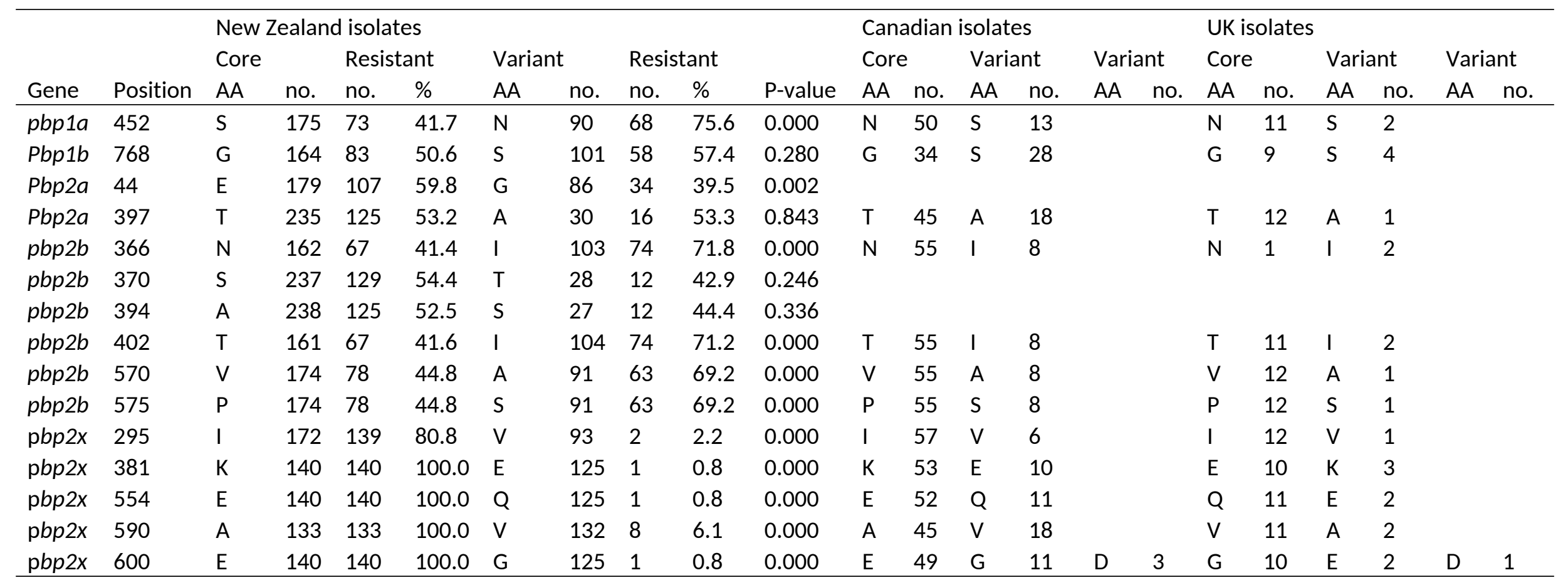




\begin{tabular}{lccccccc}
\hline & \multicolumn{3}{c}{$\mathrm{E}_{381} \mathrm{~K}$ substitution } & \multicolumn{3}{c}{ No substitution } \\
& Mean & $\mathrm{SEM}$ & $\mathrm{MIC}_{50}$ & Mean & $\mathrm{SEM}$ & MIC $_{50}$ & P-value \\
\hline Penicillin & 0.24 & 0.09 & 0.25 & 0.05 & 0.02 & 0.0625 & 0.05 \\
Cefuroxime & 0.63 & 0.27 & 0.5 & 0.06 & 0.11 & 0.025 & 0.05 \\
Ceftiofur & 1.52 & 1.47 & 1.0 & 0.15 & 0.13 & 0.025 & 0.05 \\
Cefquinome & 0.23 & 0.15 & 0.25 & 0.03 & 0.01 & 0.025 & 0.05 \\
Cefalexin & 0.34 & 0.22 & 0.25 & 0.51 & 0.29 & 0.5 & 0.05 \\
\hline
\end{tabular}

